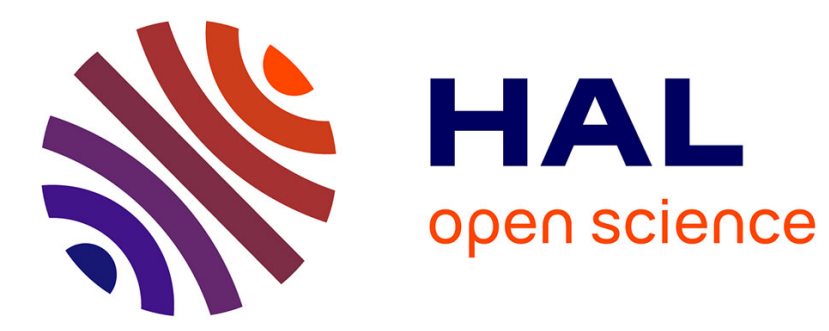

\title{
Experimental investigation of natural convection near a wall containing phase change material
}

Damien David, Frédéric Kuznik, Jean-Jacques Roux

\section{To cite this version:}

Damien David, Frédéric Kuznik, Jean-Jacques Roux. Experimental investigation of natural convection near a wall containing phase change material. International Journal of Thermal Sciences, 2016, 104, pp.281-291. 10.1016/j.ijthermalsci.2016.01.011 . hal-01848111

\section{HAL Id: hal-01848111 \\ https://hal.science/hal-01848111}

Submitted on 24 Jul 2018

HAL is a multi-disciplinary open access archive for the deposit and dissemination of scientific research documents, whether they are published or not. The documents may come from teaching and research institutions in France or abroad, or from public or private research centers.
L'archive ouverte pluridisciplinaire HAL, est destinée au dépôt et à la diffusion de documents scientifiques de niveau recherche, publiés ou non, émanant des établissements d'enseignement et de recherche français ou étrangers, des laboratoires publics ou privés. 


\title{
Experimental Investigation of Natural Convection Near a Wall Containing Phase Change Material
}

\author{
Damien DAVID ${ }^{\mathrm{a}, *}$, Frédéric KUZNIK ${ }^{\mathrm{b}}$, Jean-Jacques ROUX ${ }^{\mathrm{b}}$ \\ ${ }^{a}$ Université de Lyon, Université Lyon 1, CETHIL UMR5008, F-69622, Villeurbanne, France \\ ${ }^{b}$ Université de Lyon, INSA-Lyon, CETHIL UMR5008 F-69621, Villeurbanne, France
}

\begin{abstract}
An experimental investigation is conducted to characterize the natural convection heat transfer along panels which contain phase change materials (PCM). A dedicated configuration has been defined for this study. In this configuration, the natural convection heat transfer is triggered by a temperature scan in the ambient air. The temperature scan is responsible for the energy storage and release in the PCM panels. The corresponding experimental set-up was built and several melting and solidification tests were performed, with different values of the ambient temperature scan speed. The tested PCM panel is the Energain@ $囚$ wallboard by $\mathrm{DuPont}^{\mathrm{TM}}$. The system first reaches a stationary regime when the PCM is fully solid or liquid. During the stationary regime, the wall to air temperature difference and the convection heat flux are constant. The phase change causes an increase of these quantities. It is characterized by a first dynamic stage, a wall temperature slowdown / retrogression process, and a second dynamic stage. The two dynamic stages are well correlated to the PCM thermal characteristics. However, the temperature slowdown / retrogression phenomenon is unexpected. It consists in an extreme slowdown of the wall surface temperature evolution, which turns into a retrogression during the solidification experiments. The temperature slowdown / retrogression has never been observed before with PCM wallboards.
\end{abstract}

Keywords: Natural Convection, Phase Change Material, Convection coefficient, PCM in Building Walls, Building Inertia.

\section{Nomenclature}

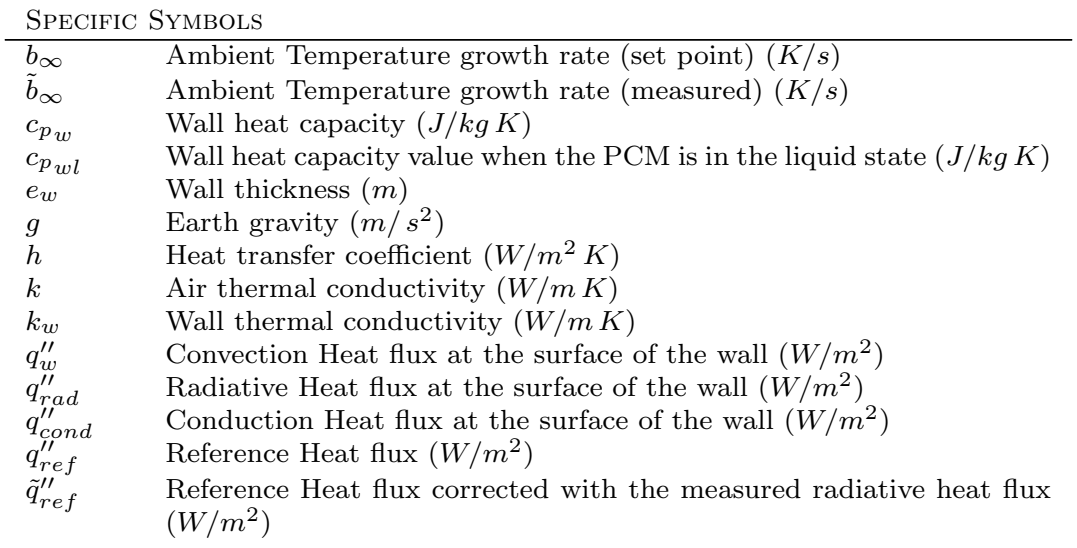

\footnotetext{
${ }^{*}$ Corresponding author. Tel.: +33-472-437-484;

Fax:+33-472-438-522

Email address: damien.david@insa-lyon.fr (Damien DAVID )
} 


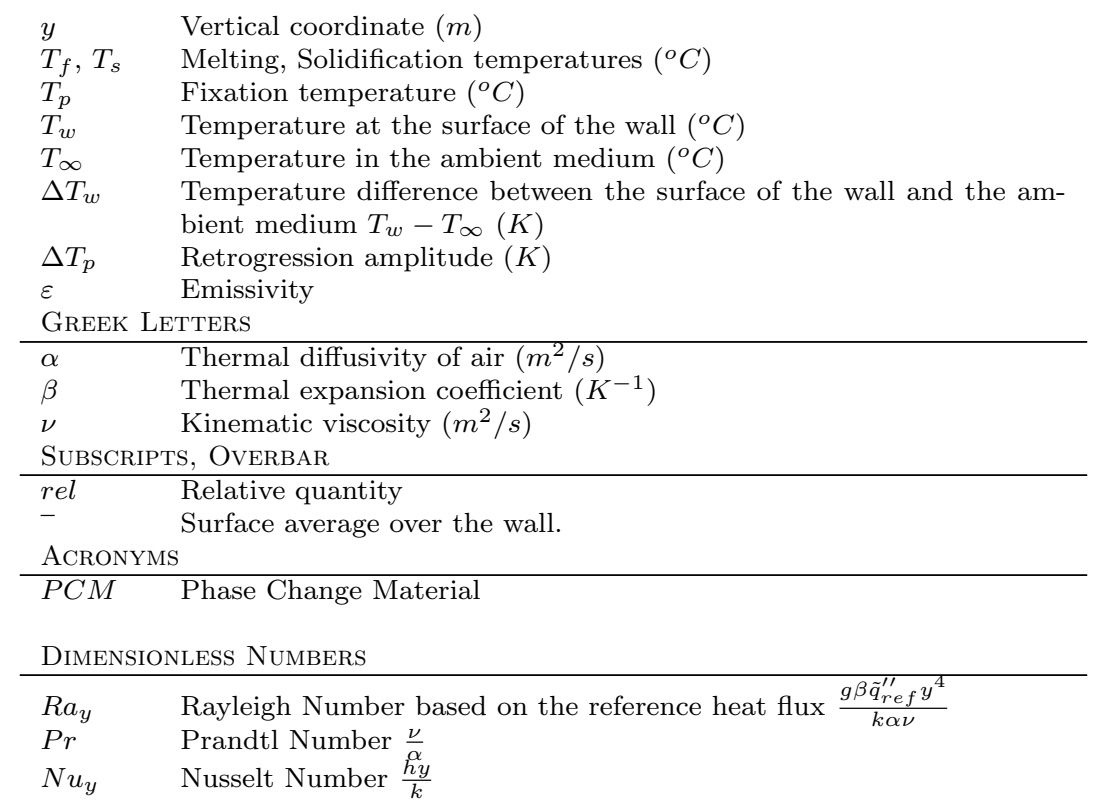

\section{Introduction}

Wallboards containing Phase Change Materials (PCMs) can be used to increase the thermal inertia of building envelopes. The potential benefits of those wallboards have already been demonstrated through several full-scale experimental studies. (Kuznik et al. [1], Liu and Awbi [2], Castell and Farid [3], Lee et al. [4] etc).

However, those panels have to be integrated into building simulation software to quantify precisely their effect on the indoor thermal comfort and the building energy consumption. Of course, such simulation is necessary to optimize PCM wallboard parameters: the phase change material, the position of the panel, the thickness of the panel...

The PCM wallboards aim to regulate the temperature within building rooms. Then, they should be located as close as possible to the interior side of the walls. In that case, the main heat transfer mode between the PCM layer and the room is natural convection. The modeling of the natural convection heat transfer between the wall and the room is decisive to get accurate predictions of PCM effect in the building.

Usually, building simulation software use an averaged heat transfer coefficient $\bar{h}$ to model the natural convection heat transfer along a wall. The determination of the value of $\bar{h}$ has a predominant impact on the simulation accuracy. Indeed, David et al. [5] confronted four correlations from the literature to simulate the amount of energy stored in a PCM layer ${ }^{1}$. They found up to $50 \%$ discrepancies in their results depending on the correlation!

Some numerical studies use a constant value of $\bar{h}$ for PCM walls simulation: Bastani et al. [6] set $\bar{h}=8 \mathrm{~W} / \mathrm{m}^{2} K$, Kong et al. [7] set $\bar{h}=8,7 \mathrm{~W} / \mathrm{m}^{2} K$, Matthieu-Potvin et al. [8] set $\bar{h}=10 \mathrm{~W} / \mathrm{m}^{2} K$, and Zhou et al. reported values ranging from $5,7 \mathrm{~W} / \mathrm{m}^{2} \mathrm{~K}$ to $12 \mathrm{~W} / \mathrm{m}^{2} \mathrm{~K}$. However, it is well known that, for natural convection, the averaged convection coefficient should depend at least on the temperature difference between the wall and the indoor environment. Moreover, those values of $\bar{h}$ was determined in a configuration without the presence of PCM in the walls.

More precise numerical studies used correlations to determine the value of the convection coefficient. David et al. [5] confronted four correlations from the literature. Evola and Marletta [9] and Soares et al. [10] used the built-in correlation from the building simulation platform EnergyPlus. Ibanez et al. [11] and Kuznik et al. [12] used the built-in correlation from the building simulation platform TRNSYS. Again, all those correlations were developed in a case of no PCM within the wall.

${ }^{1}$ Correlations developed for non-PCM walls. 


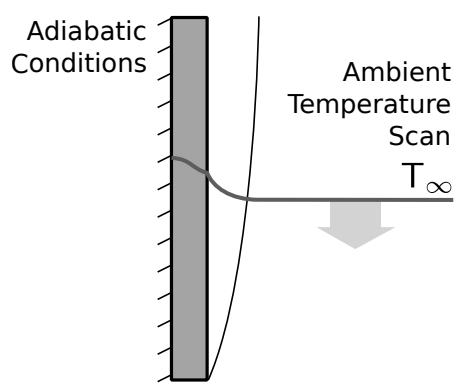

Figure 1: Studied configuration

An interesting experimental feature of the convection heat transfer coefficient seems to exist in large-scale tests. Kuznik et al. [1] and Liu and Awbi [2] performed experiments in full-scale test rooms with PCM wallboards. Both authors observed a heat transfer intensification along the PCM walls during the phase change. They estimated the convection heat transfer coefficient, and they obtained values far above the values predicted by the correlations from the literature. More recently, Sun et al. [13] observed a similar phenomenon along the faces of a cube filled with PCM.

This phenomenon needs to be deeply investigated to understand the rising convective heat transfer coefficient, and to model accurately the heat exchanges in buildings. Then, in this paper, we propose to present experimental investigations of natural convection along PCM walls.

Most of the studies about natural convection over a flat plate are based on configurations not suitable for the study of the natural convection heat transfer over a PCM wallboard. Indeed, imposing a static temperature difference between the plate and the environment, or a constant heat flux near the plate does not reflect the heat transfer mechanisms occurring along building walls containing PCM. The first step of the study is the definition of an original configuration, which enables to reproduce these mechanisms. This original configuration is described in the first section of the paper.

The two following sections concern the experimental device, in which the studied configuration is reproduced. A description of the experimental apparatus is given is Sec.3. The experimental protocol is explained in Sec.4. The remaining sections are dedicated to the analysis of the experimental results.

\section{Studied configuration}

\subsection{Description}

The studied configuration is represented in Fig.1. It is a semi-infinite vertical flat wall with adiabatic conditions on the back side. The temperature of the whole system is homogeneous at the beginning of each test. The heat transfer is triggered by a temperature scan in the ambient air:

$$
T_{\infty}(t)=T_{\infty, 0}+b_{\infty} \times t
$$

The geometry of the present configuration is similar to the geometry of the configuration used by Neeper [14], Zhou et al. [15] or Bastani et al. [6] to study PCM wallboards effects. It reproduces one of the heat transfer phenomena occurring in real buildings. The fluctuation of the air temperature within the room is due to the internal heat gains (heating or cooling systems, occupancy, sun...) and the heat transfers through the other walls. This temperature fluctuation causes a heat storage / release in the PCM wall. The heat transfer mechanism between the air and the PCM wall is natural convection.

To be consistent with the temperature evolution observed in real buildings, the value of the temperature scan speed $b_{\infty}$ should lies between $-2{ }^{\circ} \mathrm{C} / h$ and $+2{ }^{\circ} \mathrm{C} / h$. 


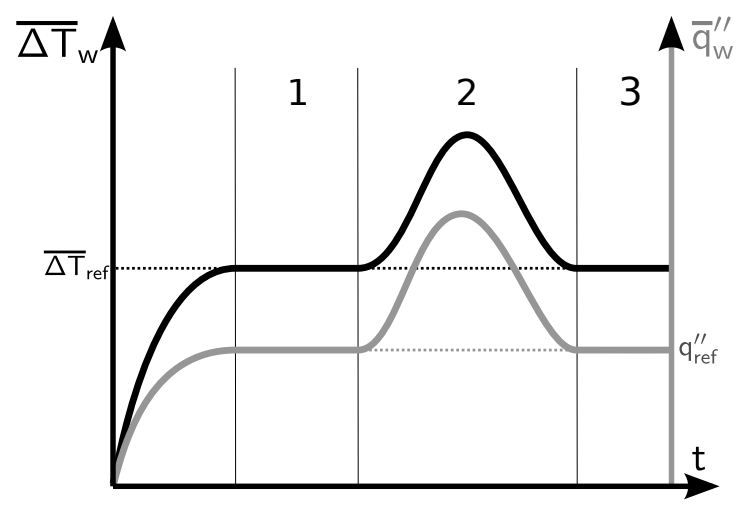

Figure 2: Expected thermal behavior of the system during a solidification experiment. 1: Stationary regime liquid phase. 2: Perturbation due to the phase change. 3: Stationary regime solid phase

\subsection{Expected behavior}

Fig. 2 shows the expected behavior of the studied configuration during a solidification process $\left(b_{\infty}<0\right)$ and through the time evolution of two quantities: the average heat flux $\bar{q}_{w}^{\prime \prime}$ over the wall, and the average temperature difference $\overline{\Delta T}_{w}=\overline{T_{w}-T_{\infty}} . \quad T_{w}$ is the wall surface temperature and $T_{\infty}$ the ambient air temperature.

At the beginning of the test, the temperature is homogeneous and equal to $T_{\infty, 0}$. Then the ambient temperature decreases. The wallboard releases energy. The quantities $\overline{\Delta T}_{w}$ and $\bar{q}_{w}^{\prime \prime}$ increase before a stabilization at the first stationary regime.

During the first stationary regime, the PCM remains in the liquid state. The temperature in the plate decreases with the same rate $b_{\infty}$ than the ambient temperature: the temperature difference $\overline{\Delta T}_{w}$ is constant. If the plate is sufficiently thin, the heat transfer within the plate along the vertical direction can be neglected. The surface heat flux $q_{w}^{\prime \prime}(y, t)$ is homogeneous and constant. It is equal to the reference heat flux $q_{r e f}^{\prime \prime}$ which depends on the wall thickness $e_{w}$, the wall density $\rho_{w}$, and the wall heat capacity when the PCM is liquid $c_{p_{w l}}$ :

$$
q_{r e f}^{\prime \prime}=-e_{w} \times \rho_{w} \times c_{p_{w l}} \times b_{\infty}
$$

The regime of interest for this study is the perturbation due to the phase change, which is represented schematically on Fig.2. The phase change in the panel causes a distortion of the heat flux and temperature profiles, which results in a modification of the heat transfer coefficient value.

A second stationary regime is reached when the phase change perturbation vanishes. During the second stationary regime, the PCM remains fully solid. The behavior of the system should be similar to the first stationary regime.

\section{Experimental set-up}

\subsection{Design of the experimental device}

The experimental device was built from an insulated cube. The inner dimensions of the cube are $2.4 \mathrm{~m} \times$ $2.4 \mathrm{~m} \times 2.4 \mathrm{~m}$. The cube is divided into two halves. During the experiments, the two half cubes are assembled to form a closed air circuit.

One half cube contains the air preparation unit (Fig.3). It is devoted to the distribution of ambient air, with a low velocity and a controlled temperature. It contains an air handling unit, an air mixing volume, and two extractions located at the top and the bottom of the cube. The air handling unit holds a blower, a heating unit $(1 \mathrm{~kW})$ and a refrigerating unit $(5 \mathrm{~kW})$. The homogeneity of the supplied air velocity is ensured by a micro-perforated membrane. The velocity of the air passing through the membrane is about $50 \mathrm{~mm} / \mathrm{s}$. A central shield redirects the air supply and extractions to the edges of the chamber. 

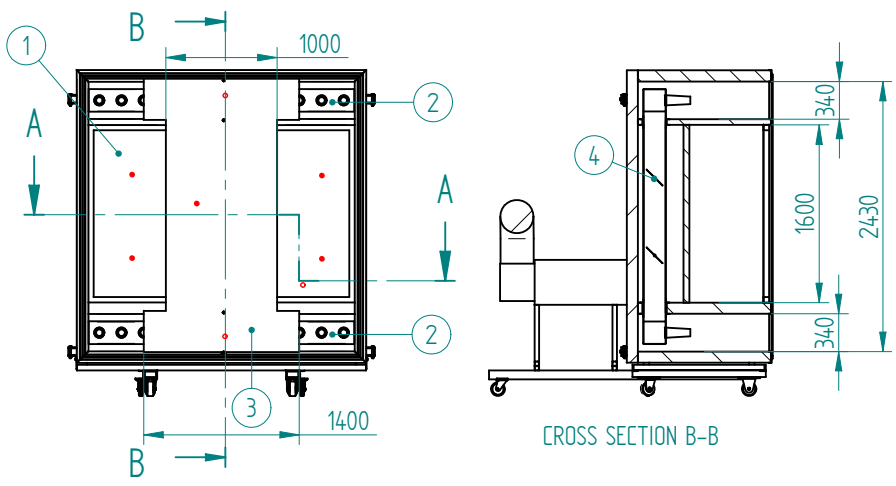

CROSS SECTION B-B

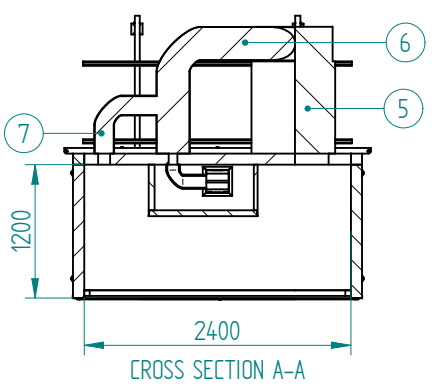

\begin{tabular}{|c|l|}
\hline \multicolumn{2}{|c|}{ Air Handling Chamber } \\
\hline 1 & Micro-perforated membrane \\
\hline 2 & Air Extractions \\
\hline 3 & Shield \\
\hline 4 & Shutters \\
\hline 5 & Air Handling Unit \\
\hline 6 & Insulated duct \\
\hline 7 & Shunt \\
\hline No & Désignation \\
\hline
\end{tabular}

Figure 3: Design of the experimental setup: air handling chamber. Surface temperature measurements are identified by red points. Air temperature measurements are identified by red circles. The air is supplied through the micro-perforated membrane. Is is extracted through the extraction openings

The second half cube contains the test chamber where the studied configuration is reproduced (Fig.4). The test chamber is fully symmetric, to reproduce the adiabatic conditions on the back side of the test walls. A sandwich made of two test walls separated by a $6 \mathrm{~mm}$ thick insulation layer is held at the center of the chamber. Each test wall is $1.6 \mathrm{~m}$ high, $0.6 \mathrm{~m}$ wide and $5 \mathrm{~mm}$ thick.

The volume in front of each test wall is divided into a test volume and a mixing volume. Those volumes are separated by a macro perforated membrane. The macro perforated membranes are safety blankets with regularly spaced $30 \mathrm{~mm}$ holes, resulting in an opening ratio of 0.5 . The air is supplied in the mixing volume, then it goes through the macro-perforated membrane to the test volume. It is drifted by the natural convection force to the openings at the top or the bottom of the macro-perforated membrane, then it is extracted through the extraction extensions.

\subsubsection{Minimization of the inlet flow perturbations}

A natural convection heat transfer along the test walls requires a quiescent ambient medium. However, the air handling system causes a residual vertical velocity $v$ and a residual horizontal velocity $w$ along the wall. The inner geometry of the test chamber,presented above, is the result of series of computational fluid dynamic simulations aiming at reducing the residual velocity. The present section provides some details about these simulations and about the criterion used to validate the geometry.

A three dimensions steady-state laminar model was used with the commercial software $\mathrm{StarCCM}+{ }^{\mathrm{T}} \mathrm{M}$. The entire volume of the test chamber was simulated. The mesh size was adjusted until we obtained a stabilization of the predicted velocities (over 2 million cells for each tested design). We applied an homogeneous heat flux $q_{w}^{\prime \prime}=5 \mathrm{~W} / \mathrm{m}^{2}$ on the test walls, and a homogeneous velocity $50 \mathrm{~mm} / \mathrm{s}$ on the micro-perforated membrane. The thermal response of the cube shell was modeled with mixed boundary conditions, in order to take into account the heat losses through the insulated panels. The ambient velocities $v$ and $w$ were selected on a vertical plane located $2 \mathrm{~cm}$ from one test wall. 

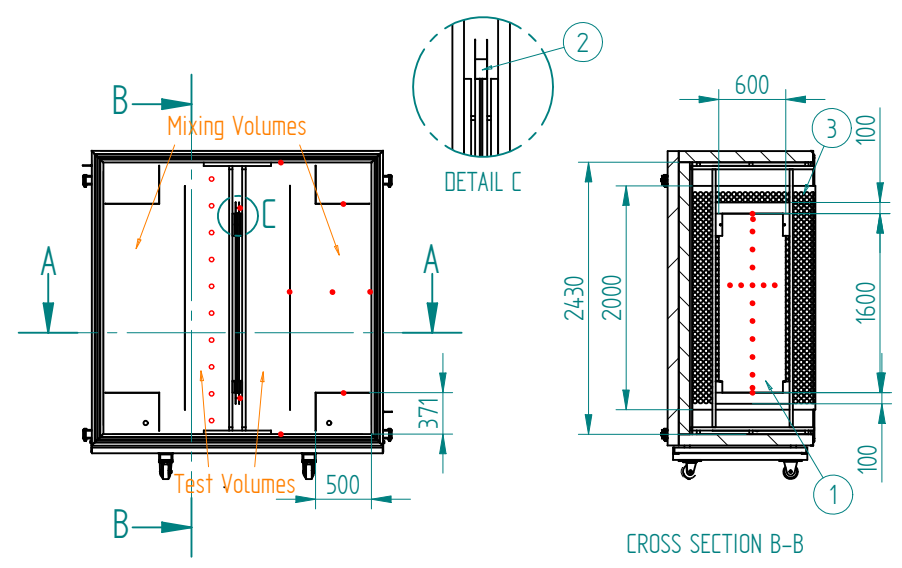

CROSS SECTION B-B

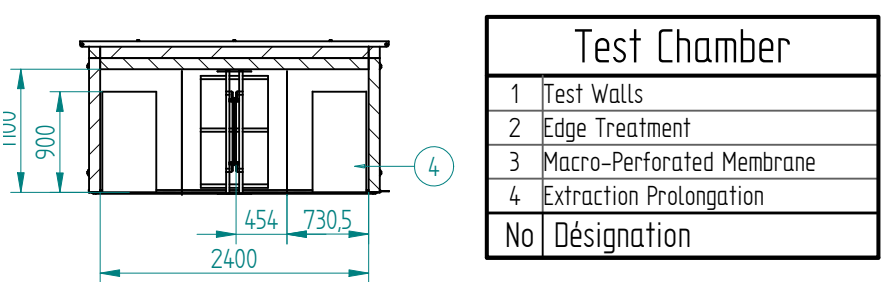

CROSS SECTION A-A

Figure 4: Design of the experimental setup: test chamber. Surface temperature measurements are identified by red points. Air temperature measurements are identified by red circles. The temperature is measured on the surface of both test walls.

The limit ambient velocities degrading the natural convection heat transfer is expressed in terms of Richardson number. The Richardson number $R i_{H}$ based on the plate height $H$ and the vertical velocity $v$ is defined as:

$$
R i_{H}=\frac{g \beta \overline{\Delta T}_{w} H}{v^{2}}
$$

Bejan [16] stated that natural convection occurs if $R i_{H}>10$. Similarly, let $R i_{W}$ be the Richardson number based on the ambient horizontal velocity $w$ and the width of the plate $W$. Siebers [17] stated that the effect of the horizontal ambient velocity is negligible when $R i_{W}>10$.

Our validation criterion was $R i_{H}>400$ and $R i_{W}>400$. It corresponds to $u<20 \mathrm{~mm} / \mathrm{s}$ and $w<$ $20 \mathrm{~mm} / \mathrm{s}$ in the ambient medium. The geometry of the test chamber was adjusted until the simulated ambient velocities fulfilled this condition all over the selected plane.

\subsubsection{Minimization of the radiative heat transfer}

We selected low emissivity materials in order to lower radiative heat transfers along the tested plates. The macro perforated membranes are made from safety blankets (gold side $\varepsilon=0.039$, silver side $\varepsilon=0.037$ ). The other surfaces are covered with aluminum sheets $(\varepsilon=0.039)$. The most emissive surface in the test chamber is the micro perforated membrane $(\varepsilon=0.612)$. The PCM test wall did not need any special treatment for radiation, since the product is already covered with aluminum foil $(\varepsilon=0.05)$. 


\subsection{Metrology}

The metrology was designed to measure the quantities required to compute 1) the heat transfer coefficient $h(y, t)$ and 2$)$ the performance indicators of the system.

\subsubsection{Temperature sensors}

Seventy-two $0.2 \mathrm{~mm}$ diameter K-type thermocouples are implemented in the experimental setup. The locations of the thermocouples are indicated in Figures 3 and 4.

The vertical profile of the test wall surface temperature $T_{w}(y, t)$ is measured on both test walls. Each profile is obtained with 11 equally spaced thermocouples plus 2 thermocouples located $50 \mathrm{~mm}$ far from the top and bottom edges.

The ambient air temperature $T_{\infty}(y, t)$ is measured using 10 thermocouples held on a vertical rack, located $200 \mathrm{~mm}$ far from the left-hand-side test wall. The remaining thermocouples are spread all over the experimental setup to feed the radiation inverse model and to compute the performance indicators.

The temperature measurement period is $120 \mathrm{~s}$. Each temperature value is the averaged over twenty raw temperature measurements recorded at the frequency of $3 \mathrm{~Hz}$. The uncertainty on the mean temperature value is $\pm 0.07^{\circ} \mathrm{C}$. The uncertainty on the difference between two mean values is $\pm 0.09^{\circ} \mathrm{C}$. The overall uncertainty of temperature measurement is $\pm 0.11^{\circ} \mathrm{C}$.

\subsubsection{Calculation of the convective heat flux}

To obtain the convective heat flux $q_{w}^{\prime \prime}$, both conduction heat flux leaving the wall $q_{\text {cond }}^{\prime \prime}$ and radiative heat flux $q_{r a d}^{\prime \prime}$ are estimated. Then, convective heat flux is deduced from $q_{w}^{\prime \prime}=q_{c o n d}^{\prime \prime}-q_{r a d}^{\prime \prime}$.

The conduction heat flux $q_{c o n d}^{\prime \prime}$ is computed using an inverse conduction method. The measured surface temperatures $T_{w}(y, t)$ are time-filtered with a Gaussian filter, and spatially interpolated with a spline interpolation scheme. These data feed a $2 \mathrm{D}$ transient conduction model which computes the temperature field over a cross section of the plate. Then, the conduction heat flux distribution is estimated at the surface of the wall. The conduction model is based on the finite volume discretization: the cross section of the wall is divided into $10 \times 160$ rectangular cells. The phase change is taken into account by using the apparent heat capacity method $c_{p_{w}}(T)$. As the problem is non-linear, an iterative method is used. The iterative method is presented in details in David et al. [5].

The distribution of the radiative heat flux $q_{r a d}^{\prime \prime}(y, t)$ is computed with a radiative model fed by surface temperature measurements. Using the symmetry of the test chamber, the geometry of the radiation model is limited to a half of the test chamber (Fig.5). The radiation model computes the radiation heat flux between 66 surfaces distributed among four rectangular cavities. The macro perforated membrane is treated as a semi-transparent surface shared between the cavities 1 and 2 . The other shared surfaces are supposed to be fully transparent. A radiation balance is computed within each cavity using the radiosity method.

The uncertainty on the radiative and conduction heat flux was determined through a Monte-Carlo procedure. The procedure took into account the uncertainty on the temperature measurements and the uncertainty on the material characteristics. The resulting uncertainty on the convective heat flux is about $8 \%$.

\section{Experimental Protocol}

\subsection{Tested PCM wallboard}

We performed the experiments with the PCM wallboard Energain $®$ by DuPont ${ }^{\mathrm{TM}}$. The wallboard contains $5 \mathrm{~mm}$ of composite material ( $60 \%$ of a paraffin mixture and $40 \%$ copolymers), covered on both sides by $120 \mu \mathrm{m}$ thick aluminum foils (Fig.6). The thermal characteristics of the panel are gathered in Tab.2, where $c_{p_{c m}}$ is the apparent heat capacity of the composite material. It was measured using a differential scanning calorimeter and with a scanning rate of $+3^{\circ} \mathrm{C} / h$.

The conduction model simulates the multi-layer panel as a unique layer of $5 \mathrm{~mm}$ equivalent material, the heat capacity and the density being adjusted to take into account the foils. The resulting equivalent heat capacity $c_{p_{w}}(T)$ is presented in Fig.7, for a melting and a solidification process. During the melting, the maximum heat capacity occurs at $T_{f}=22.2^{\circ} \mathrm{C}$. During the solidification, it occurs at $T_{s}=17.8^{\circ} \mathrm{C}$. 

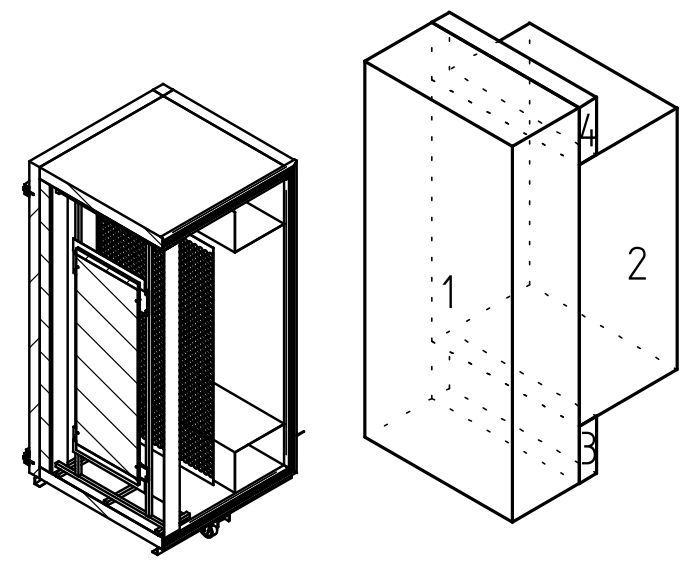

Figure 5: Geometry of the radiation model (right). Correspondence with the inner geometry of the test chamber (left)

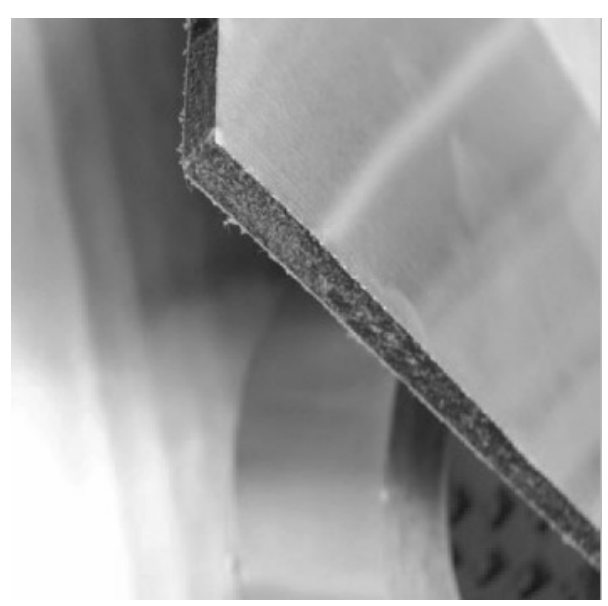

Figure 6: The Energain ${ }^{T M}$ product

\subsection{Settings}

The results of six experiments are presented in the present paper. The experiments D10, D15, and D20 correspond to decreasing ambient temperature scans with an initial ambient temperature of $40^{\circ} \mathrm{C}$ and a final ambient temperature of $5{ }^{\circ} \mathrm{C}$. The temperature scan speeds are respectively $b_{\infty}=-1{ }^{\circ} \mathrm{C} / h,-1.5^{\circ} \mathrm{C} / h$, and $-2^{\circ} \mathrm{C} / h$.

The experiments I10, I15 and I20 correspond to increasing ambient temperature scans, with an initial ambient temperature of $5^{\circ} \mathrm{C}$ and a final ambient temperature of $40^{\circ} \mathrm{C}$. The temperature scan speeds are respectively $b_{\infty}=1{ }^{\circ} \mathrm{C} / h, 1.5^{\circ} \mathrm{C} / h$, and $2^{\circ} \mathrm{C} / h$.

Each experiment is preceded by a 6 hours pre-conditioning at the initial temperature to ensure a homogeneous temperature in the system.

\subsection{Performance indicators}

The quality of the experimental device and tests are evaluated through 4 performance indicators. These indicators are computed from the temperature measurements. Tab.3 reports the average values of the performance indicators during the first stationary regime of each experiment. 


\begin{tabular}{lllll}
\hline & $e$ & $\rho$ & $c_{p}$ & $k$ \\
& {$[\mathrm{~mm}]$} & {$\left[\mathrm{kg} / \mathrm{m}^{3}\right]$} & {$[k J / k g K]$} & {$[W / m K]$} \\
\hline \hline Composite material & 5 & 853 & $c_{p_{c m}}(T)$ & 0.2 \\
\hline Aluminum foils & $2 \mathrm{x} 0.12$ & 2700 & 0.897 & - \\
\hline Equivalent panel & 5 & 853 & $c_{p_{c m}}+0.148$ & 0.2 \\
\hline
\end{tabular}

Table 2: Thermal characteristics of the Energain ${ }^{\top M}$ panels

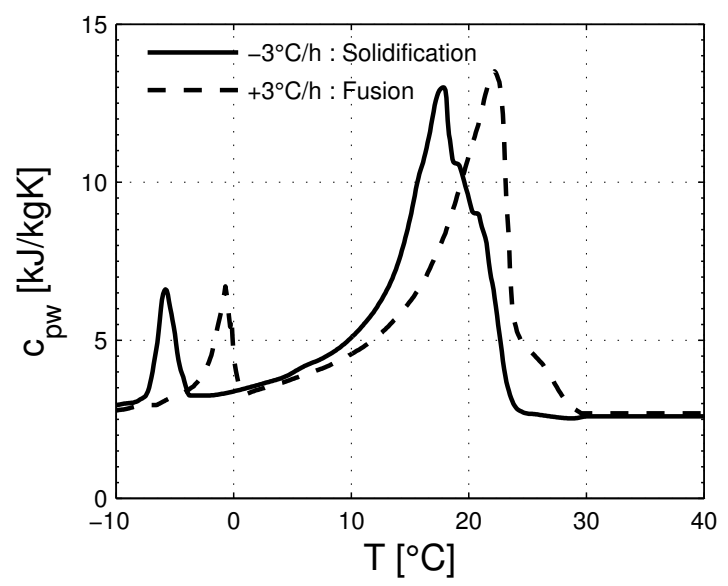

Figure 7: Equivalent heat capacity of the Energain ${ }^{T M}$ Panel. The melting curve was obtained with a scanning rate of $+3^{\circ} \mathrm{C} / h$. The solidification curve was obtained with a scanning rate of $-3{ }^{\circ} \mathrm{C} / h$.

The absolute value of the measured ambient temperature scan speed $\tilde{b}_{\infty}$ is slightly lower than the set point. This discrepancy does not degrade the quality of the measurements.

The ambient vertical thermal stratification $\Gamma_{\infty}$ lies between $0.2^{\circ} \mathrm{C} / m$ and $0.5^{\circ} \mathrm{C} / \mathrm{m}$. These values are comparable to the smallest stratification values observed in similar setups from the literature: $0.2^{\circ} \mathrm{C} / m$ for Pivovano et al. [18], $0.5^{\circ} \mathrm{C} / m$ for Tsuji and Nagano [19], $1.8^{\circ} \mathrm{C} / m$ for Cheesewright [20].

The default of symmetry is quantified from the temperature profiles $T_{w 1}(y)$ and $T_{w 2}(y)$ measured at the surface of both test walls. $\Delta T_{s}$ is the maximum value of the difference between both profiles: $\Delta T_{s}=\max _{y}\left|T_{w 1}(y)-T_{w 2}(y)\right|$. It represents nearly $8 \%$ of the wall to air temperature difference when the temperature scan is low. It reduces to $3 \%$ when the temperature scan is faster. The parasitic heat flux which results from this default of symmetry is negligible due to the layer of insulation material separating the two wallboards.

The radiative heat flux $q_{r a d}^{\prime \prime}$ does not excess $7.5 \%$ of the conduction heat flux. It is generally higher near the leading edge of the plate, which might cause a slight distortion of the convection heat flux profile.

The discrepancies between the experimental setup and the ideal studied configuration are integrated into a new definition of the reference heat flux $q_{r e f}^{\prime \prime}$. This new definition takes into account the measured values

\begin{tabular}{ll|llllll}
\hline Test & & $\mathrm{D} 10$ & $\mathrm{D} 15$ & $\mathrm{D} 20$ & $\mathrm{I} 10$ & $\mathrm{I} 15$ & $\mathrm{I} 20$ \\
\hline Set point $b_{\infty}$ & {$\left[{ }^{\circ} \mathrm{C} / h\right]$} & -1 & -1.5 & -2 & 1 & 1.5 & 2 \\
\hline$\tilde{b}_{\infty}$ & {$\left[{ }^{\circ} \mathrm{C} / h\right]$} & -0.94 & -1.39 & -1.87 & 0.95 & 1.36 & 1.85 \\
$\Gamma_{\infty}$ & {$\left[{ }^{\circ} \mathrm{C} / m\right]$} & 0.12 & 0.26 & 0.29 & 0.22 & 0.35 & 0.5 \\
$\Delta T_{s} / \Delta T_{w}$ & {$[\%]$} & 7.9 & 4.2 & 2.7 & 6.6 & 5 & 3 \\
$q_{\text {rad }}^{\prime \prime} / q_{\text {cond }}^{\prime \prime}$ & {$[\%]$} & 7.3 & 6.5 & 5.8 & 7.5 & 7.3 & 7.2
\end{tabular}

Table 3: Average value of the four performance indicators during the first stationary regime 
of the temperature scan speed $\tilde{b}_{\infty}$, and the average radiative heat flux over the plate $\bar{q}_{\text {ray }}^{\prime \prime}$ :

$$
\tilde{q}_{r e f}^{\prime \prime}=e_{w} \times \rho_{w} \times c_{p_{w l}} \times \tilde{b}_{\infty}-\bar{q}_{r a y}^{\prime \prime}
$$

\section{4. conclusion}

The experimental apparatus was designed to measure the evolution of the natural convection heat transfer characteristics along a PCM panel. Those characteristics are the wall to air temperature profile $\Delta T_{w}(y)=$ $T_{w}(y)-T_{\infty}(y)$ and the convection heat flux profile $q_{w}^{\prime \prime}(y)$. The heat transfer coefficient $h(y)=q_{w}^{\prime \prime}(y) / \Delta T_{w}(y)$ is deduced from those two quantities.

The measurement results are presented in the three following sections. In section 5 , the stationary regime is we fully characterized. In sections 6 and 7 , the phase change regime is examined.

\section{Temperature and heat flux profiles during the stationary regime}

The first stationary regime occurs when the wall temperature difference profiles and the heat flux profiles stabilize. The stationary regime was observed during all the experiments, just before the phase change in the walls. In this section, the characteristics of the heat transfer along the wall during this particular regime are analyzed.

\subsection{Analysis of the temperature and heat flux profiles}

The temperature difference and heat flux profiles given in Fig. 8 were obtained by averaging the measured data over a $40 \mathrm{~min}$ time period, during the first stationary regime of experiments D10, D15, and D20.

The heat flux $q_{w}^{\prime \prime}$ is nearly homogeneous along the plates for all the experiments. The slight distortions observed for experiments D15 and D20 are due to a non-homogeneous distribution of the radiative heat flux. The agreement between the mean heat flux value and the reference heat flux $\tilde{q}_{r e f}^{\prime \prime}$ (Eq.4) is excellent.

The temperature difference profiles $\Delta T_{w}(y)$ highlight two heat transfer regimes along the plate. At the bottom of the plate, $\Delta T_{w}$ grows with the vertical coordinate $y$. This is the bottom zone regime (BZ). After a transition located around $y=0.5 m, \Delta T_{w}$ stabilizes. This is the top zone regime (TZ).

A correlation was built to characterize the natural convection heat transfer during the stationary regime. This correlation is a combination of two correlations: one for the bottom zone regime, and one for the top zone regime. Both correlations are expressed as functions of the Rayleigh number $R a_{y}$ based on the reference heat flux:

$$
R a_{y}=\frac{g \beta \tilde{q}_{r e f}^{\prime \prime} y^{4}}{k \alpha \nu}
$$

They are combined with the formalism from Churchill and Usagi [21]:

$$
N u_{y}=\left[\left(\alpha_{B Z} R a_{y}^{1 / 5}\right)^{n}+\left(\alpha_{T Z} R a_{y}^{1 / 4}\right)^{n}\right]^{1 / n}
$$

The exponent $1 / 5$ corresponds to a laminar convection flow, with a homogeneous heat flux on the plate, and without thermal stratification in the ambient medium. This is the regime expected at the bottom of the plate. The exponent $1 / 4$ corresponds to a homogeneous temperature difference along the plate.

The coefficients $\alpha_{B Z}, \alpha_{T Z}$ and $n$ were computed through successive least square method. Their numerical values are given in Tab.4. They lead to an excellent agreement between the correlation and the measurement results for both heat transfer regimes (Fig.9). 

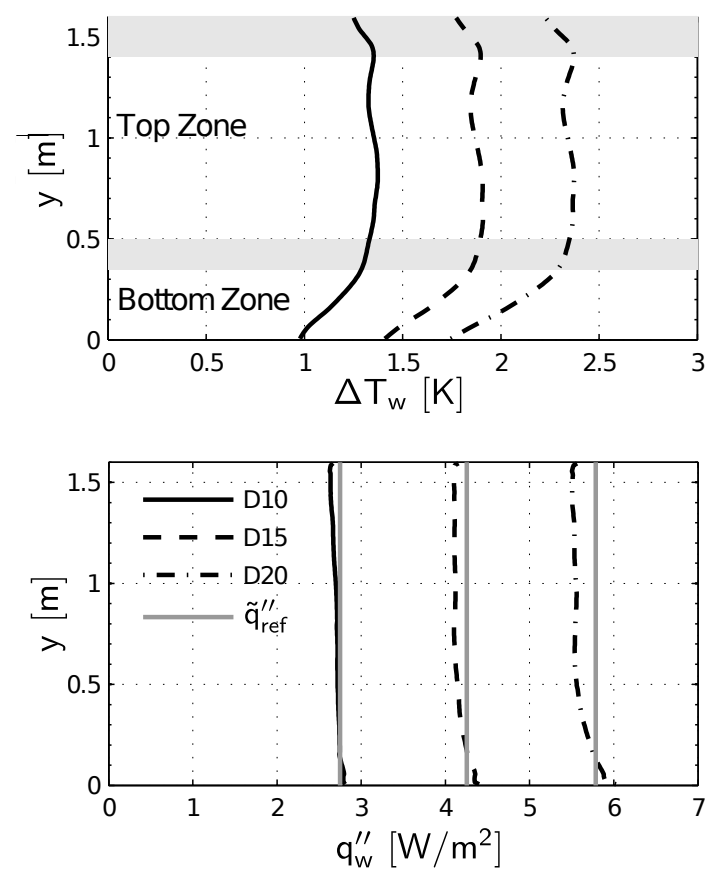

Figure 8: Temperature difference and heat flux profiles during the stationary regime

\begin{tabular}{llll}
\hline & $\alpha_{B Z}$ & $\alpha_{T Z}$ & $n$ \\
\hline \hline Energain $^{\mathrm{TM}}$ & 0.635 & 0.235 & 25 \\
\hline Gypsum Board & 0.607 & 0.229 & 25 \\
\hline
\end{tabular}

Table 4: Coefficients of the correlations. Comparison with natural convection along a gypsum board

\subsection{Reproducibility of the stationary regime}

During the stationary regime, only sensible heat is stored in the PCM wall. This regime should occur whatever the material composing the wallboard. Additional tests were conducted with gypsum boards, in order to assess the reproducibility of the measurements.

Similarly to Energain ${ }^{T \mathrm{M}}$ tests, a bottom zone and a top zone regime were observed. Correlations were built by following the same procedure. The resulting coefficients $\alpha_{B Z}, \alpha_{T Z}$ and $n$ are given in Tab.4. They are in accordance with the coefficient obtained for Energain ${ }^{\mathrm{TM}}$ product (within 5\%). The stationary regime was successfully reproduced in both cases, assessing the reproducibility of the measurements.

\subsection{Comments}

There are numerous literature references about natural convection over a vertical flat plate subjected to an homogeneous heat flux. Those references propose two ways of interpreting the transition between the bottom zone regime and the top zone regime: either it is due to a transition between a laminar flow regime and a turbulent flow regime, or it is due to the ambient thermal stratification.

At the bottom of the plate, a laminar flow regime is expected, without ambient thermal stratification effects. Sparrow and Gregg [22] provide the corresponding correlation coefficient $\alpha_{B Z}=0.52$, which is nearly $20 \%$ lower than the measured coefficient.

At the top of the plate, either a fully turbulent flow regime or a fully stratified medium is expected. Vliet and Liu [23] and Armfield et al. [24] provide the respective correlation coefficients: $\alpha_{T Z}=0.17$ and $\alpha_{T Z}=\left[k \Gamma_{\infty} /\left(4 \tilde{q}_{r e f}^{\prime \prime}\right)\right]^{1 / 4} \approx 0.13$. Again, these coefficient values are lower than the measured values. 


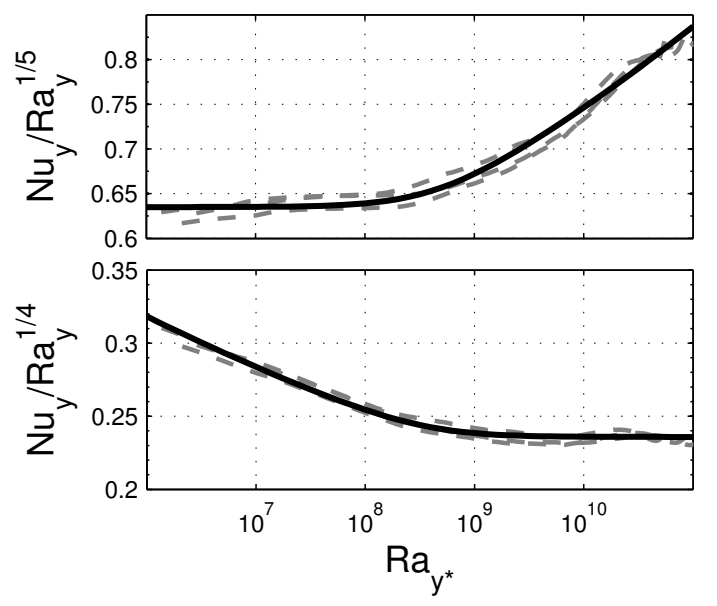

Figure 9: Comparison between the correlation (black lines) and the measurement data (gray dashed lines), during the stationary regime, for experiments D10 D15 and D20.

There are two potential explanations for the discrepancies between the measurement results and the literature coefficients. First, the studied configuration is not exactly the classical configuration of the vertical flat plate with a constant heat flux, since the heat transfer is generated by a decrease of the ambient temperature. Then, the top zone regime can be due to a combination of stratification and turbulent effects. However, this interaction is not studied in the literature so far.

\section{An overview of the phase change perturbation}

This section focuses on the representation of the measurement results given in Fig.10. In this figure, the measured quantities are represented in terms of average relative quantities, as a function of the average wall temperature $\bar{T}_{w}$. Since the overall temperature of the system is decreasing during the experiments D10, D15 and D20, the curves must be read from the right side (high temperatures) to the left side (low temperatures).

There are several justifications for using this representation. First, this is the only representation which enables a global appreciation of the system behavior during the whole duration of the three experiments. The first stationary regime is identified with the number 1, and the phase change perturbation is decomposed into three stages $2 \mathrm{a}, 2 \mathrm{~b}$ and $2 \mathrm{c}$. The second stationary regime is not reached.

The fact that we use relative values emphasis the deviation of the natural convection characteristics due to the phase change inside the wall. Since the quantities are averaged over the wall surface, they correspond to the quantities used in building simulation codes. By analyzing the evolution of the average relative convection coefficient $\bar{h}_{r e l}$, it is possible to determine a way to modulate the average convection coefficient $\bar{h}$ in building simulation codes in order to take into account the presence of PCM.

\subsection{Definition of the average relative quantities}

The relative wall surface heat capacity $c_{p_{r e l}}=c_{p_{w}}\left(\bar{T}_{w}\right) / c_{p_{w l}}$ is reminded on each graphic. The PCM is fully liquid between $35^{\circ} \mathrm{C}$ and $25^{\circ} \mathrm{C}$ : this temperature range corresponds to the first stationary regime.

$\overline{\Delta T}_{w}, \bar{q}_{w}^{\prime \prime}$, and $\bar{h}=\bar{q}_{w}^{\prime \prime} / \overline{\Delta T}_{w}$ are the averaged values over the wall surface of the wall temperature difference, the convective heat flux and the convective heat transfer coefficient. The average relative quantities express the deviation of those average quantities from the values they would have during the stationary regime. They highlight the effect of the phase change on convection heat transfer characteristics.

The relative average heat flux $\bar{q}_{r e l}^{\prime \prime}$ the ratio between $\bar{q}_{w}^{\prime \prime}$ and the reference heat flux $\tilde{q}_{r e f}^{\prime \prime}$ from Equation 4. The relative convection heat transfer coefficient is $\bar{h}_{\text {rel }}=\bar{h} / h_{\text {stat }}$, where $h_{\text {stat }}$ is the mean value of $\bar{h}$ 


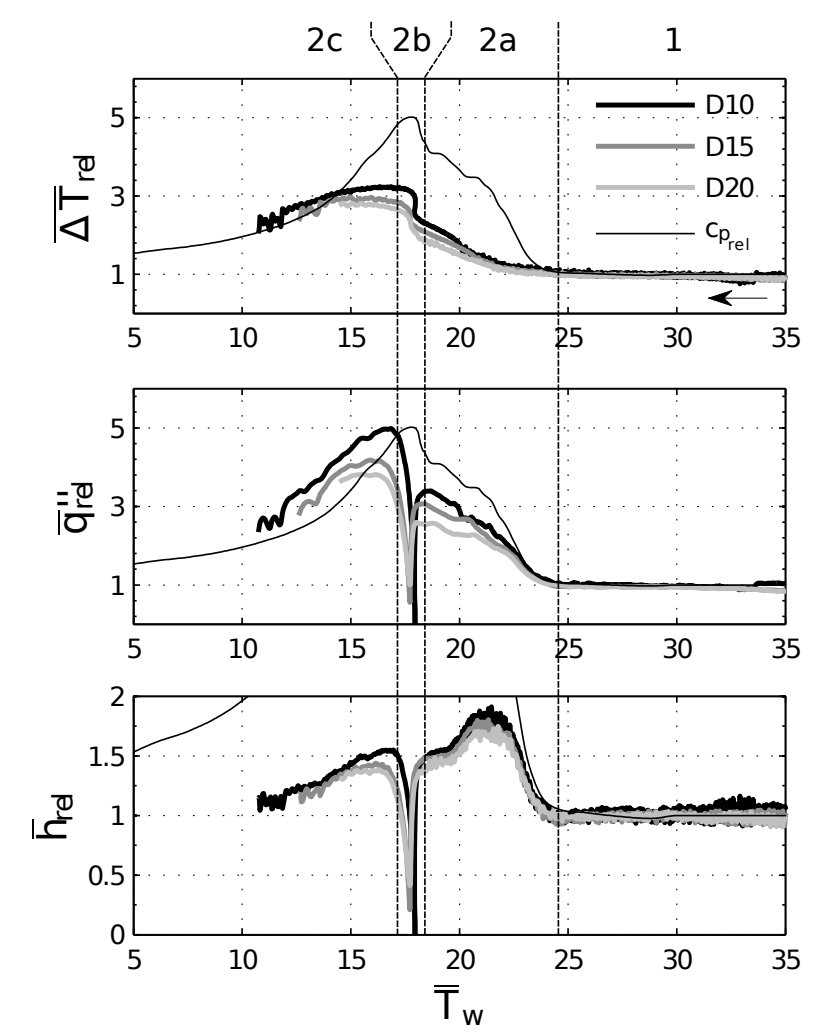

Figure 10: Surface average relative heat flux $\bar{q}_{r e l}^{\prime \prime}$, relative temperature difference at the plate $\overline{\Delta T}_{r e l}$, relative heat transfer coefficient $\bar{h}_{r e l}$, as a function of the average wall surface temperature $\bar{T}_{w}$. Measurement results from experiments D10, D15, and D20

during the whole duration of the stationary regime. The value of $h_{\text {stat }}$ is $2.3 \mathrm{~W} / \mathrm{m}^{2} \mathrm{~K}$ for experiment D10, $2.45 \mathrm{~W} / \mathrm{m}^{2} \mathrm{~K}$ for experiment $D 15$, and $2.65 \mathrm{~W} / \mathrm{m}^{2} \mathrm{~K}$ for experiment D20. The average relative wall surface temperature difference is $\overline{\Delta T}_{r e l}=\overline{\Delta T}_{w} /\left(h_{\text {stat }} . \tilde{q}_{r e f}^{\prime \prime}\right)$.

As expected, the values of $\overline{\Delta T}_{r e l}, \bar{q}_{r e l}^{\prime \prime}$ and $\bar{h}_{r e l}$ are stable and equal to 1 during the stationary regime.

\subsection{Beginning of the phase change regime: prior dynamic stage (2a)}

At the beginning of the phase change regime, the PCM solidification slows down the decrease of the wall surface temperature. Since the ambient temperature still decreasing at the rate $b_{\infty}$, the relative temperature difference $\overline{\Delta T}_{r e l}$ increases. Similarly, the surface heat flux $\bar{q}_{r e l}^{\prime \prime}$ increases due to higher values of the material heat capacity. The deviations of $\bar{q}_{r e l}^{\prime \prime}$ and $\overline{\Delta T}_{r e l}$ are more pronounced when the evolution of the ambient temperature is slow.

The phase change process also results in an increase of the convective heat transfer coefficient: $\bar{h}_{r e l}>1$. Unlike the evolution of $\bar{q}_{r e l}^{\prime \prime}$ and $\overline{\Delta T}_{r e l}$, the evolution of $\bar{h}_{r e l}$ appears to be nearly independent on the ambient temperature increase rate (see maximum values given in Tab.5).

However the evolution of the heat transfer coefficient is closely related to the evolution of the PCM heat capacity: at the beginning of the phase change process, $c_{p_{r e l}}$ rises quickly, leading to high values of $\bar{h}_{r e l}$, then the evolution of $c_{p_{r e l}}$ slows down, and $\bar{h}_{r e l}$ reaches smaller values. It is possible to express the value of the relative convection coefficient as a function of the slope of the $c_{p_{r e l}}$ curve:

$$
\bar{h}_{r e l}\left(\bar{T}_{w}\right)=1+0.73 \times\left|\frac{\partial c_{p_{r e l}}}{\partial T}\left(\bar{T}_{w}+1.2\right)\right|^{0.4}
$$


The temperature shift $\bar{T}_{w}+1.2$ is justified by the time needed to diffuse the heat inside the plate. For a melting process, this temperature shift would be $\bar{T}_{w}-1.2$.

\subsection{Temperature slowdown / retrogression (2b)}

After the first stage of the phase change regime, the temperature differences $\overline{\Delta T}_{r e l}$ exhibit a sudden increase. This evolution indicates that the wall surface temperature slows down, while the ambient temperature still decreasing.

This event is located with an average fixation temperature $\left(\overline{T_{w}}\right)_{p}$. This is the average wall temperature for which the quantity $\left|\partial \bar{T}_{w} / \partial t\right|$ is minimum. The values of the average fixation temperature are given in Tab.5. They are very close to the heat capacity maximum temperature: $T_{s}=17.8^{\circ} \mathrm{C}$.

The temperature slowdown turns into a temperature retrogression for experiment D10. During this experiment, a slight but non-null increase of the average wall temperature is measured, while the ambient temperature still decreasing.

The slowdown / retrogression of the wall temperature is not an instantaneous process. The duration of this event $\Delta t_{p}[h]$ is given in Tab.5. It lasts for at least 2 hours during each experiment.

Obviously, the heat flux model predicts a sudden drop of the heat flux, causing a similar drop of the convection coefficient. However, given the unexpected behavior of the wall temperature, it is not possible to have confident in the heat flux predictions. This is particularly true for experiment D10, where the temperature retrogression cannot be interpreted by an excessive increase of the wall heat capacity.

\subsection{End of the phase change regime: second dynamic stage (2c)}

The second dynamic stage happens when the wall temperature difference decreases, i.e. when the wall surface temperature decreases faster than the ambient air temperature. The rapid evolution of the wall temperature leads to higher heat flux values.

The value of the relative convection coefficient $\bar{h}_{r e l}$ at the beginning of the second dynamic stage is similar to its value at the end of the first dynamic stage. Then, the coefficient decreases gradually.

There are little discrepancies on the values of the convection coefficient $\bar{h}_{r e l}$ between the three tests. These discrepancies are mainly due to the temperature stabilization which is more pronounced for test D10. Despite these discrepancies, it is to have a relatively good estimation of the relative convection coefficient by expressing this coefficient in a similar way than for the first dynamic stage:

$$
\bar{h}_{r e l}\left(\bar{T}_{w}\right)=1+0.6 \times\left|\frac{\partial c_{p_{r e l}}}{\partial T}\left(\bar{T}_{w}\right)\right|^{0.7}
$$

\begin{tabular}{lllll}
\hline Regime & Quantities & D10 & D15 & D20 \\
\hline \hline $2 \mathrm{a}$ & $\max \left[\bar{h}_{r e f}\right]$ & 1,82 & 1,75 & 1,70 \\
\hline & $\left(\bar{T}_{w}\right)_{p}\left[{ }^{\circ} \mathrm{C}\right]$ & 17.96 & 17.73 & 17.73 \\
$2 \mathrm{~b}$ & $\Delta t_{p}[h]$ & 3.4 & 2.5 & 1.8 \\
\hline
\end{tabular}

Table 5: Analysis of the mean quantities evolutions

\subsection{Comments}

During experiments D10, D15 and D20, the three stages of the phase change process are well correlated with the PCM thermal characteristics: the first and second dynamic stages correspond to the increase and decrease of the apparent heat capacity, the temperature stabilization occurs when the wall heat capacity is maximum. There was no such correlation during the melting tests I10, I15, and I20. That is the reason why the results of the melting experiments were not presented in this section.

The temperature slowdown / retrogression phenomenon is an unexpected event existing for all the experiments. During this event, the heat flux predictions are not reliable. However, it is possible to analyze the way it materializes on the evolution of the wall surface temperature profiles. This is the purpose of the next section. 

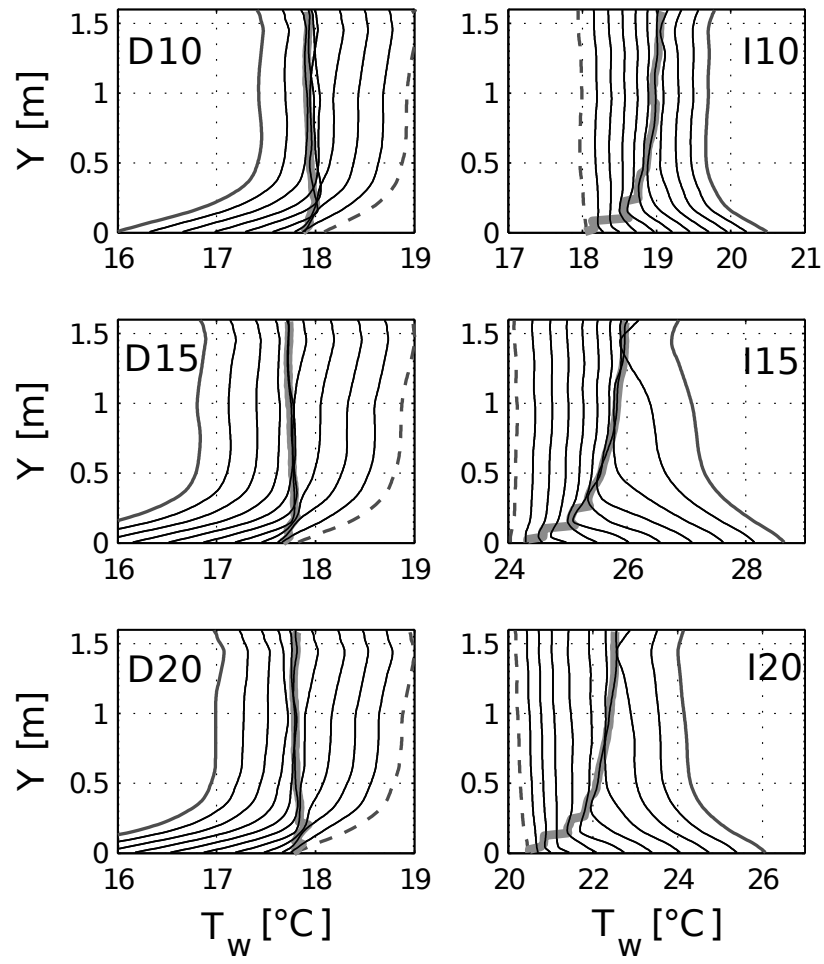

Figure 11: Localization of the fixation temperature $T_{p}(y)$ on sequences of wall temperature profiles. The first curve of each sequence is the bold dashed curve, the last curve is the bold full curve. The fixation temperature is located on the thick gray curve

\section{The wall temperature slowdown / retrogression}

Fig.11 shows, for each test, a sequence of measured wall temperature profiles around the temperature slowdown / retrogression event. The profile evolution should be read from the right side to the left side for the tests D10, D15, and D20. They should be read from the left side to the right side for the tests I10, I15, and I20. For those tests, the $y$-axis was reversed to locate the leading edge of the plate at the bottom of the curve.

The temperature profiles at the beginning and at the end of each sequence are typical from the tworegime heat transfer observed during the stationary regime: there is a bottom zone regime (the temperature grows along the $y$ coordinate) and a top zone regime (the surface temperature difference is homogeneous). The structural distribution of the heat transfer along the plate is not modified during the first and second dynamic stages of the phase change process.

The time interval between each temperature profile is constant within each plot. The temperature slowdown / retrogression manifests itself through a high concentration of temperature profiles all along the plate. To characterize this phenomenon, two quantities are introduced: the fixation temperature $T_{p}(y)$ and the retrogression amplitude $\Delta T_{p}(y)$. These two quantities are explicitly presented in Fig.12. The fixation temperature is the temperature having the slowest evolution. The retrogression amplitude is the amplitude of the wall temperature fluctuation during the retrogression. These quantities are computed all along the $y$ coordinate. 


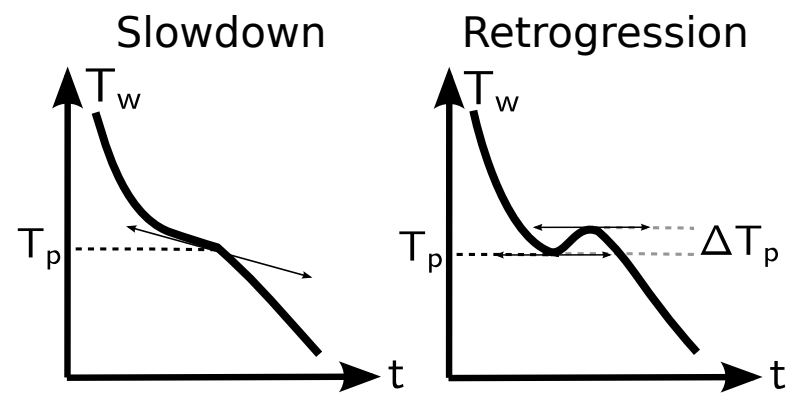

Figure 12: The fixation temperature effect: slowdown or retrogression. Definition of the fixation temperature $T_{p}$ and retrogression amplitude $\Delta T_{p}$ in both cases

\subsection{Decreasing temperature tests}

Fig.13 contains the profiles of $T_{p}(y)$ and $\Delta T_{p}(y)$ for experiments D10, D15, and D20. The solidification temperature $T_{s}$ is also presented. The fixation temperature $T_{p}$ lies within the interval $T_{s} \pm 0.2^{\circ} \mathrm{C}$. Given the uncertainty on the temperature measurements, and the uncertainty on the determination of $T_{s}$, it is possible to assume that the temperature slowdown / retrogression phenomenon occurs at the solidification temperature.

The retrogression amplitude is higher at the center of the top zone $(y \approx 1 \mathrm{~m})$. The maximum retrogression values $\Delta T_{p}$ were obtained during experiment D10. During experiment D20, the retrogression occurs on a limited area of the wall.

\subsection{Increasing ambient temperature}

The temperature slowdown phenomenon also occurred during experiments I10, I15 and I20. Fig.14 displays the profiles of $T_{p}(y)$ and $\Delta T_{p}(y)$ for experiments I10, I15 and I20. The melting temperature $T_{f}$ is also indicated. Here, the retrogression amplitudes are much smaller. They lie in the interval of the temperature measurement error. We mostly observe a temperature slowdown phenomenon.

The shapes of the fixation temperature profiles $T_{p}(y)$ are very different during the increasing temperature experiments. Figure 12 shows that the temperature slowdown phenomenon is triggered at the leading edge of the plate $y=0$ (i.e. at the top side of the plate). Then, this phenomenon propagates all along the plate (toward the bottom direction of the plate). However, during the time taken by the slowdown phenomenon to propagate, the temperature of the rest of the plate increases: that is the reason why the fixation temperature gets higher when $y$ increases in Fig.14.

An other aspect of the present results is surprising: it is the temperature at which the phenomenon is triggered. This temperature is $18^{\circ} \mathrm{C}$ for experiment $\mathrm{I} 10,24.3^{\circ} \mathrm{C}$ for experiment I10, and $20.5^{\circ} \mathrm{C}$ for experiment I10. Those temperature are not coherent with the associates ambient temperature rates $b_{\infty}$. They are very different from the melting temperature $T_{f}=17.8^{\circ} \mathrm{C}$.

\subsection{Comments}

The temperature slowdown and retrogression effect is clearly driven by different mechanisms during the decreasing and the increasing ambient temperature experiments.

For the decreasing tests, the temperature slowdown / retrogression occurs nearly at the solidification temperature $T_{s}$ all along the plate: this is a local phenomenon. This phenomenon may possibly find an interpretation in the sub-cooling effect. The sub-cooling effect would cause sudden heat releases which would reheat locally the plate near the surface, leading to a local increase of the plate surface temperature.

For the increasing tests, the retrogression is negligible. However, the temperature slowdown is not anymore a local phenomenon. It is triggered at the leading edge of the wall, then it is transported all along the wall. The transport of the temperature slowdown phenomenon might occur within the wall, or within the boundary layer, which would suggest a complex coupling between the PCM panel and the natural convection boundary layer. The triggering of the temperature slowdown occurs at a nearly random temperature. 

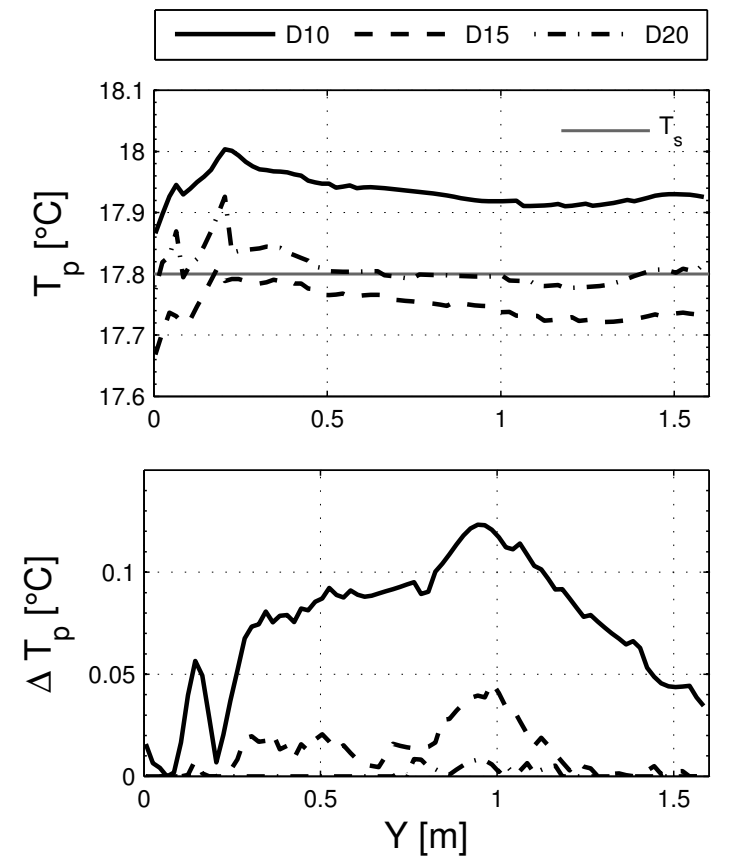

Figure 13: Fixation temperature $T_{p}$ and retrogression value $\Delta T_{p}$ profiles for experiments D10, D15 and D20

\section{Conclusions}

The results of the present study reveal the complexity of the interactions between a plate containing phase change materials and a natural convection boundary layer. We designed a configuration specially dedicated to the study of those interactions. The corresponding experimental setup was built. As expected, the thermal behavior of the whole system undergoes a stationary regime which is now well understood. Then, the phase change occurs within the plate: it strongly modifies the transfer characteristics at the surface of the plate.

The effect of the phase change can be split into three consecutive stages: the first dynamic stage, the wall surface temperature slowdown / retrogression, and the second dynamic stage.

During the first and the second dynamic stages, the deviation of the average convective heat transfer coefficient is well correlated to the PCM characteristics. It does not depend on the ambient temperature growth rate. This deviation is expressed as a relative heat flux $\bar{h}_{r e l}$, and two correlations was built to predict the value $\bar{h}_{r e l}$ from the evolution of the PCM relative heat capacity. The first one (Eq.7) is valid before the heat capacity peak, the other one (8) is valid after the peak. Those correlations can be integrated in building simulation codes, in order to modulate the natural convection heat transfer coefficient for a wall containing PCM. Of course, this is a first approximation of the PCM effect as the correlations do not take into account the temperature slowdown / retrogression phenomenon.

The temperature slowdown / retrogression phenomenon consists in an extreme slow down of the wall surface temperature. The detailed analysis of the wall surface temperature profiles highlighted two different mechanisms: one for the solidification tests, and one for melting tests. For the solidification tests, the phenomenon is local. It could be explained by the presence of subcooling within the PCM. For the melting tests, the phenomenon is randomly triggered near the leading edge of the plate. Then, it is propagated along the plate.

The behavior of the system is not fully understood during the temperature slowdown / retrogression event. But if we want to go further in the interpretation of the experimental results, more accurate PCM models are required. These models should be able to predict subcooling in order to fully characterize the 

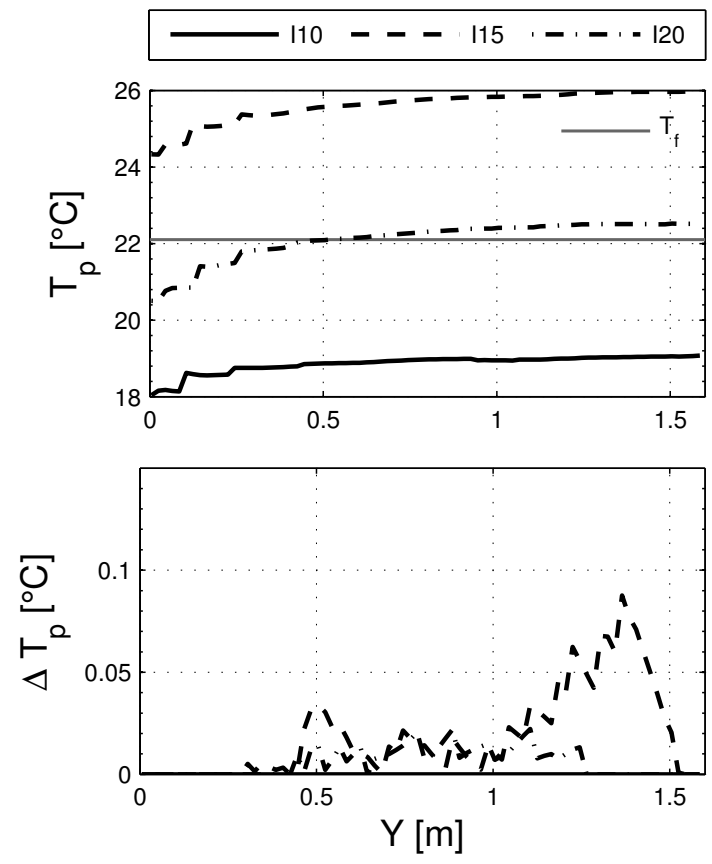

Figure 14: Fixation temperature $T_{p}$ and retrogression value $\Delta T_{p}$ profiles for experiments I10, I15 and I20

solidification test. They should be able to integrate the random behavior of the material near the leading edge effect during the melting tests. And finally, they will need to be coupled with a fluid dynamics model in order to to predict the transport mechanism occurring during those melting tests.

\section{References}

\section{References}

[1] F. Kuznik, J. Virgone, and J. J. Roux. Energetic efficiency of room wall containing pcm wallboard: a full scale experiment. Energy And Buildings, 40:148-156, 2008.

[2] Hongim Liu and Hazim B. Awbi. Performance of phase change material boards under natural convection. Building and Environment, 44(9):1788 - 1793, 2009.

[3] Albert Castell and Mohammed M. Farid. Experimental validation of a methodology to assess PCM effectiveness in cooling building envelopes passively. Energy and Buildings, 81:59-71, October 2014.

[4] Kyoung Ok Lee, Mario A. Medina, Erik Raith, and Xiaoqin Sun. Assessing the integration of a thin phase change material (PCM) layer in a residential building wall for heat transfer reduction and management. Applied Energy, 137:699-706, January 2015.

[5] D. David, F. Kuznik, and J.-J. Roux. Numerical study of the influence of the convective heat transfer on the dynamical behavior of a phase change material wall. Applied Thermal Engineering, 31:3117-3124, 2011.

[6] Arash Bastani, Fariborz Haghighat, and Janusz Kozinski. Designing building envelope with PCM wallboards: Design tool development. Renewable and Sustainable Energy Reviews, 31:554-562, March 2014.

[7] Xiangfei Kong, Shilei Lu, Yiran Li, Jingyu Huang, and Shangbao Liu. Numerical study on the thermal performance of building wall and roof incorporating phase change material panel for passive cooling application. Energy and Buildings, 81:404-415, October 2014.

[8] Fran??ois Mathieu-Potvin and Louis Gosselin. Thermal shielding of multilayer walls with phase change materials under different transient boundary conditions. International Journal of Thermal Sciences, 48(9):1707-1717, September 2009.

[9] Gianpiero Evola and Luigi Marletta. The Effectiveness of PCM Wallboards for the Energy Refurbishment of Lightweight Buildings. Energy Procedia, 62:13-21, 2014.

[10] N. Soares, A. R. Gaspar, P. Santos, and J. J. Costa. Multi-dimensional optimization of the incorporation of PCM-drywalls in lightweight steel-framed residential buildings in different climates. Energy and Buildings, 70:411-421, February 2014.

[11] Manuel Ibanez, Ana Lazaro, Belen Zalba, and Luisa F. Cabeza. An approach to the simulation of PCMs in building applications using TRNSYS. Applied Thermal Engineering, 25(11-12):1796-1807, August 2005. 
[12] Fr?d?ric Kuznik, Joseph Virgone, and Kevyn Johannes. Development and validation of a new TRNSYS type for the simulation of external building walls containing PCM. Energy and Buildings, 42(7):1004-1009, July 2010.

[13] Xiaoqin Sun, Quan Zhang, Mario A. Medina, and Kyoung Ok Lee. Experimental observations on the heat transfer enhancement caused by natural convection during melting of solide-liquid phase change materials (PCMs). Applied Energy.

[14] D. A. Neeper. Thermal dynamics of wallboard with latent heat storage. Solar Energy, 68(5):393 - 403, 2000.

[15] D. Zhou, G. S. F. Shire, and Y. Tian. Parametric analysis of influencing factors in Phase Change Material Wallboard (PCMW). Applied Energy, 119:33-42, April 2014.

[16] A. Bejan. Convection Heat Transfer. John Wiley \& Sons, 2004.

[17] D.L. Siebers, R.J. Moffat, and R.G. Schwind. Experimental mixed convection from a large, vertical plate in a horizontal flow. In IN: Heat transfer 1982; Proceedings of the Seventh International Conference. -, -, 1982.

[18] A. Pirovano, S. Viannay, and M. Jannot. Convection naturelle en r?gime turbulent la long d'une plaque plane verticale. In Proceedings of the 4th International Heat Transfer Conference, Paris-Versailles, France. -, -, 1970.

[19] T. Tsuji and Y. Nagano. Characteristics of a turbulent natural convection boundary layer along a vertical flat plate. International Journal of Heat and Mass Transfer, 31:1723-1734, 1988.

[20] R. Cheeswright. Turbulent natural convection from a vertical flat plate. Journal of Heat Transfer, 90:1-8, 1968.

[21] Stuart W. Churchill. Transient, laminar free convection from a uniformly heated vertical plate. Letters in Heat and Mass Transfer, 2(4):311 - 314, 1975.

[22] E.M. Sparrow and J.L. Gregg. Laminar free convection from a vertical plate with uniform surface heat flux. Tansaction of the ASME, 78:435, 1956.

[23] G.C. Vliet and C. Ross. Turbulent natural convection on upward and downward facing inclined constant heat flux surfaces. Journal of Heat Transfer, 97:549-555, 1975.

[24] S.W. Armfield, J.C. Patterson, and W. Lin. Scaling investigation of the natural convection boundary layer on an evenly heated plate. International Journal of Heat and Mass Transfer, 50:1592-1602, 2007. 